\title{
OBSTÁCULOS À INOVAÇÃO E PORTE DAS EMPRESAS INDUSTRIAIS NO BRASIL: RUMO A POLÍTICAS PÚBLICAS DE INCENTIVO À INOVAÇÃO MAIS ASSERTIVAS'
}

\author{
Tulio Chiarini² \\ Vanessa Criscuolo Parreiras de Oliveira ${ }^{3}$ \\ Marcia Siqueira Rapini ${ }^{4}$
}

As evidências fornecidas neste artigo contribuem para a proposição de políticas que sejam mais assertivas, de acordo com seu objetivo: i) incentivar que as empresas que não inovam comecem a fazê-lo; e ii) incentivar que as firmas que já inovam façam mais, inclusive que consigam lidar com maiores níveis de incerteza, gerando produtos e processos com maior grau de novidade. Contudo, essas duas diretrizes precisam ser balizadas pelo tamanho das empresas. Portanto, ao realizar-se uma análise exploratória e descritiva dos obstáculos à inovação nas empresas brasileiras, procurase neste trabalho encontrar elementos para corroborar a seguinte proposição: os obstáculos econômicos - e institucionais -, tecnológicos e organizacionais são fatores que dificultam e impedem processos inovativos em empresas inovadoras e não inovadoras, respectivamente; no entanto, o porte da firma - seja esta inovadora ou não - importa. Isto é, quanto maior o tamanho da empresa - de acordo com o número de empregados -, menos obstáculos esta enfrenta para inovar vis-à-vis as médias e micro e pequenas empresas (MPEs).

Palavras-chave: inovação; obstáculos à inovação; porte de empresas; Pintec.

\section{OBSTACLES TO INNOVATION AND THE SIZE OF INDUSTRIAL COMPANIES IN BRAZIL: TOWARDS MORE ASSERTIVE POLICIES TO ENCOURAGE INNOVATION}

The evidences provided in this article contribute to the proposition of public policies which are more assertive according to their objective: i) to encourage non-innovators to start innovating; ii) to encourage companies that already innovate to do more, even to deal with higher levels of uncertainty, generating products and processes with a greater degree of novelty. However, these two guidelines need to be considered taking into account the size of companies. Therefore, when conducting an exploratory and descriptive analysis of the obstacles to innovation in Brazilian companies, we seek to find elements to corroborate the following proposition: economic (and institutional), technological and organizational obstacles are factors that hinder and impede innovative processes in both 'innovative' and 'non-innovative' companies, however, the size of the company (whether innovative or not) matters. That is, the larger the size of a company (according to the number of employees) the fewer obstacles it faces to innovate vis-à-vis medium and small and micro enterprises (SMEs).

Keywords: innovation; obstacles to innovation; firm size; Pintec.

1. DOI: http://dx.doi.org/10.38116/ppp56art2

2. Analista em ciência e tecnologia (C\&T) do Instituto Nacional de Tecnologia (INT). ORCID: https://orcid.org/0000-0002-3758-8413. E-mail:<tulio.chiarini@int.gov.br>.

3. Pesquisadora em nível de pós-doutorado do Programa de Pós-Graduação em Economia da Universidade Federal Fluminense (PPGE/UFF). ORCID: https://orcid.org/0000-0002-1153-7466. E-mail: <vparreiras@uol.com.br>.

4. Professora do Centro de Desenvolvimento e Planejamento Regional da Universidade Federal de Minas Gerais (Cedeplar/ UFMG). ORCID: 0000-0002-8035-3003.E-mail:<msrapini@cedeplar.ufmg.br.>. 


\section{OBSTÁCULOS PARA LA INNOVACIÓN Y EL TAMAÑO DE LAS EMPRESAS INDUSTRIALES EN BRASIL: HACIA POLÍTICAS PÚBLICAS MÁS ASERTIVAS PARA FOMENTAR LA INNOVACIÓN}

La evidencia proporcionada en este artículo contribuye a proponer políticas que sean más coherentes con su propósito i) incentivar a las empresas que no innovan a que comiencen a innovar; ii) incentivar que las empresas que ya innovan lo hagan más, e incluso que logren lidiar con mayores niveles de incertidumbre, generando productos y procesos con un mayor grado de novedad. Sin embargo, estas dos directrices necesitan ser focalizadas según el tamaño de las empresas. Por lo tanto, al realizarse un análisis exploratorio y descriptivo de los obstáculos a la innovación en las empresas brasileñas, se busca en ese trabajo encontrar elementos para corroborar la siguiente proposición: los obstáculos económicos (e institucionales), tecnológicos y organizacionales son factores que dificultan e impiden procesos innovadores en empresas innovadoras y no innovadoras, sin embargo, el tipo de empresa (sea innovadora o no) importa. Esto es, a mayor tamaño de la empresa (de acuerdo con el número de empleados) menos obstáculos se enfrenta a innovar vis-à-vis las medianas y micro o pequeñas empresas.

Palabras clave: innovación; obstáculos a la innovación; tamaño de la empresa; Pintec.

\section{OBSTACLES À L'INNOVATION ET DIMENSION DES ENTREPRISES INDUSTRIELLES AU BRÉSIL: POUR DES POLITIQUES PUBLIQUES DE SOUTIEN À L'INNOVATION PLUS AFFIRMÉES}

Les preuves fournies dans cet article contribuent à permettre de proposer des politiques publiques mieux adaptées à leurs objectif : i) inciter les entreprises qui n'innovent pas à innover; ii) inciter les entreprises qui innovent déjà à innover davantage, y compris à gérer des niveaux d'incertitude plus élevés en générant des produits et des processus plus novateurs. Cependant, pour suivre ces directives, il faut tenir compte de la taille des entreprises. Par conséquent, lors d'une analyse exploratoire et descriptive des obstacles à l'innovation dans les entreprises brésiliennes, nous cherchons des éléments permettant de corroborer la proposition suivante: les obstacles économiques (et institutionnels), technologiques et organisationnels sont des facteurs qui entravent les processus d'innovation dans les deux domaines (entreprises innovantes et non innovantes), cependant, la taille de l'entreprise (qu'elle soit innovante ou non) est importante. Plus une entreprise est grande, moins elle a d'obstacles pour innover, par rapport aux PME et aux micro-entreprises.

Mots-clés: innovation; obstacles pour innover; taille des enterprises; Pintec.

JEL: 010; 025; 032; L52.

\section{INTRODUÇÃO}

Há crescente preocupação dos formuladores de políticas públicas com os elementos que afetam processos inovativos em empresas. A avaliação dos obstáculos ao seu insucesso possui relevância econômica, uma vez que sua remoção ou mitigação pode ampliar a população de firmas inovadoras e aumentar o desempenho daquelas já existentes (D’este et al., 2012). 
A literatura empírica internacional recente com foco em inovação tem devotado crescente atenção à percepção dos obstáculos à inovação e ao seu impacto (desencorajador) sobre as decisōes das empresas de engajarem-se em atividades inovativas, à intensidade desse engajamento e à propensão a inovar (Pellegrino e Savona, 2013; Coad, Pellegrino e Savona, 2016). Há, todavia, escassa discussão no Brasil sobre o papel dos obstáculos à inovação nas empresas industriais de acordo com seu porte, e este artigo procura ser uma contribuição nesse sentido. ${ }^{5}$ Desse modo, busca-se identificar e examinar dados empíricos que corroboram a seguinte proposição: os obstáculos econômicos - e institucionais -, tecnológicos e organizacionais são fatores que dificultam e impedem processos inovativos tanto em empresas industriais inovadoras quanto em não inovadoras; no entanto, o porte da firma - seja esta inovadora ou não - importa. Isto é, quanto maior o tamanho da empresa menos obstáculos esta enfrenta para inovar vis-à-vis as firmas de menor porte. Isso está de acordo com a literatura econômica, a qual afirma que empresas grandes possuem, além de ganhos na escala produtiva, concentraçáo de recursos financeiros, mas não somente estes - para inovar (Chandler Junior, 1990; Penrose, 2006; Schumpeter, 2008).

Para encontrar elementos que sustentem a proposição anterior, são utilizados dados da Pesquisa de Inovação do Instituto Brasileiro de Geografia e Estatística (Pintec/IBGE), abrangendo os resultados das últimas seis edições (Pintecs 2003, 2005, 2008, 2011, 2014 e 20176). São analisados dados relativos aos problemas e obstáculos à inovação encontrados pelas empresas no desenvolvimento de suas atividades inovativas, levando-se em conta seu porte - cuja proxy é o número de empregados: micro e pequenas empresas (MPEs), médias e grandes empresas. As evidências fornecidas pela Pintec contribuem para a formulação de políticas públicas mais assertivas de acordo com seu objetivo: i) incentivar que empresas industriais que não inovam comecem a inovar; e ii) incentivar que empresas industriais que já inovam continuem a fazê-lo.

$\mathrm{O}$ artigo está estruturado da seguinte maneira. $\mathrm{Na}$ seção 2, são apresentados argumentos que mostram a importância do processo inovativo do ponto de vista da teoria econômica evolucionária e, também, a relevância de se analisar os obstáculos ao processo de inovação. $\mathrm{Na}$ seção 3, é revelada a base de dados. $\mathrm{Na}$ seção 4, são apresentados os dados sobre os obstáculos à inovação nas empresas brasileiras por porte, propondo-se uma discussão. Por fim, a seção 5 abarca as consideraçôes finais e proposiçôes que visam auxiliar a formulação de políticas públicas, de acordo com o porte e o objetivo da política.

5. É possível citar os seguintes trabalhos recentes que tratam sobre a temática no Brasil: Rapini (2013), Kühl e Cunha (2013), Oliveira e Bertoni (2014), Oliveira (2015), Maia e Silva-Filho (2016), Silva-Filho, Braga e Rebouças (2017) e Rapini, Chiarini e Bittencourt (2017). Podemos ainda citar o Relatório de Fiesp (2010).

6. Disponivel em: <https://is.gd//niWlm>. 


\section{CONTRIBUIÇÕES TEÓRICAS E EMPÍRICAS}

\subsection{Processo de inovação e seus obstáculos}

$\mathrm{Na}$ teoria evolucionária, as empresas são entendidas como organizaçôes que “aprendem" (Malerba, 1992; Lundvall e Johnson, 1994; Nelson e Winter, 2005). Desse modo, o processo de aprendizado é essencial para que estas possam compreender suas estratégias e possam conceber suas trajetórias de aquisição de competências necessárias à geração de processos inovativos capazes de criar assimetrias no processo concorrencial. Este, por sua vez, é um processo cumulativo, o qual permite a diferenciação entre as empresas e, por conseguinte, seu desempenho. Essas diferenças resultam de distintas estratégias, as quais gerarão empresas com variadas estruturas e competências, incluindo-se aquelas relacionadas às atividades inovativas (Nelson, 1991).

A inovação bem-sucedida depende da combinação, por parte das empresas, de uma gama ilimitada de competências (Borrás e Edquist, 2015), incluindo-se a capacidade para acessar financiamentos, entender as necessidades e demandas da sociedade, contratar mão de obra qualificada e estabelecer interaçóes efetivas com outras organizaçóes.

Assim, a falta de entendimento do mercado, a ausência de mão de obra qualificada e a falta de interação com demais organizaçóes são obstáculos ao processo inovativo. No entanto, as barreiras à inovação não se resumem aos obstáculos internos às empresas causados pela falta - ou deficiência - de competências-chave (Conner e Prahalad, 1996). Há barreiras que decorrem do ambiente no qual a empresa está inserida, podendo ser: i) deficiências de mercado (externalidades, assimetria de informaçóes e custos de transaçóes); ii) predomínio - ou ausência - de certas instituiçôes (Acemoglu e Robinson, 2012); e iii) características dos sistemas de inovação (Lundvall, 1992).

Nesse contexto, é possível classificar as barreiras quanto a sua natureza, sendo estas internas ou externas às empresas (Hadjimanolis, 2003). D'este et al. (2012) notam que as empresas inovadoras são necessariamente compelidas a lidar com muitas barreiras (externas e internas); contudo, algumas são dissuadidas do engajamento de processos inovativos por causa dessas dificuldades e permanecem "travadas" às rotinas já estabelecidas - isso é o que se chama de efeito lock-in - e acabam por não inovar - são as denominadas empresas não inovadoras. Portanto, essas empresas falham em trazer novos produtos ou processos ao mercado, devido à incapacidade de superar tais obstáculos com que se deparam durante o processo inovativo.

Dadas a complexidade do processo inovativo e a multiplicidade de interaçóes envolvidas, as barreiras possuem caráter dinâmico e podem afetar distintos estágios do processo inovativo (Hadjimanolis, 2003). Portanto, estas não eram preexistentes 
à inovação, mas desenvolveram-se durante o processo inovativo, adicionando dificuldade a sua avaliação e superação ( $o p$. cit.). As barreiras podem afetar não apenas diretamente as empresas, mas também indiretamente, atuando em diferentes organizaçóes intermediárias do processo de inovação, como bancos e concorrentes (Piatier, $1984^{7}$ apud Hadjimanolis, 2003); ou seja, afetando diferentes atores do sistema de inovação. Ademais, distintas barreiras podem agir não de forma isolada, mas de forma complementar, levando a círculos viciosos (Mohnen e Rosa, 2001), podendo impactar negativamente o processo ao provocar desde atrasos na superação das barreiras até mesmo sua completa interrupção (Hadjimanolis, 2003).

Cabe ainda relativizar a universalidade das barreiras à inovação, uma vez que sua natureza, sua frequência e seu impacto provavelmente variam de acordo com o contexto ao qual a empresa desempenha suas atividades inovativas. De acordo com Hadjimanolis (2003), há diferentes padróes de constrangimentos em contextos específicos. Tais contextos incluem o tipo de inovação, o tipo de inovador, o tamanho da empresa, o setor ao qual a empresa pertence, sua localização geográfica e, provavelmente, os ciclos de negócios (op. cit.). Na próxima subseção, a questão concernente ao porte da empresa será discutida.

No entanto, antes de prosseguir, é preciso reconhecer que a eliminação dos obstáculos ao processo inovativo não necessariamente garante inovaçôes, uma vez que inovar é um fenômeno complexo e não linear (Etzkowitz e Leydesdorff, 2000; Arthur, 2009). A remoção - ou minimização - das barreias é necessária, porém não suficiente para garantir o sucesso das inovaçóes (Hadjimanolis, 2003). Ademais, náo se está assumindo aqui que toda e qualquer barreira ao processo inovativo seja algo negativo e que deva ser eliminada. Vale ressaltar que algumas barreiras podem ter efeitos positivos, ao estimular processos de aprendizado e experiência para as empresas (Tang e Yeo, 2003).

\subsection{Obstáculos à inovação e porte das empresas}

$\mathrm{O}$ tamanho das empresas provavelmente determina não apenas a natureza, mas também a importância das barreiras à inovação, e as pequenas firmas são as que percebem seus impactos como os mais severos (Hadjimanolis, 2003). Alguns trabalhos abordam os problemas e os obstáculos ao desenvolvimento de MPEs e médias empresas. Segundo Zevallos (2003), as condiçóes nas quais essas empresas se desenvolvem na América Latina não lhes são particularmente favoráveis. Isso está em grande parte relacionado às suas competências endógenas (baixo grau de adoção tecnológica, pouca qualificação de seus trabalhadores e/ou do próprio empresário, fragilidade administrativa e baixa produtividade) e também a certas condiçôes do ambiente, que as afetam em maior grau do que às grandes firmas.

7. Piatier, A. Barriers to innovation. London: Frances Pinter Publishers Ltd., 1984. 260 p. 
Molina-Ycaza e Sánchez-Riofrío (2016) acrescentam que os principais obstáculos para o desenvolvimento das MPEs e médias empresas nesses países são o acesso ao financiamento e à tecnologia e a falta de recursos humanos especializados.

Obstáculos que se referem aos limitados recursos tangíveis e intangíveis são apresentados em estudos, que analisam os processos inovativos tanto em MPEs quanto em médias empresas (Rothwell, 1989; Freel, 2000; Hewitt-Dundas, 2006; Molina-Ycaza e Sánchez-Riofrío, 2016). Segundo Hewitt-Dundas (2006), por exemplo, a probabilidade de as pequenas e grandes firmas empreenderem inovação é fortemente influenciada pelos seus constrangimentos de recursos e pelas capacidades herdados de um período para o seguinte. Todavia, a falta de recursos financeiros, as limitadas oportunidades de mercado e as pressóes legislativas ou regulatórias são mais significativas para as pequenas empresas.

Freel (2000) argumenta que pequenas empresas enfrentam restriçóes concernentes à ausência de trabalho tecnicamente qualificado; ao uso restrito de informação e competências externas; à dificuldade em atrair/manter financiamentos e falta de capacidade relacionada para disseminar o risco; à inadequação da gestáo original para além da prescriçáo inicial; e aos custos imódicos da conformidade regulatória. Conforme o autor, as limitações ao processo inovativo em pequenas empresas podem ser divididas em quatro conjuntos de componentes principais: i) financeiros; ii) gestão e marketing; iii) mão de obra qualificada; e iv) informação.

É interessante notar que são escassos os trabalhos que abordam os obstáculos à inovação de MPEs e médias empresas com base nos surveys de inovação. Oliveira e Bertoni (2014) encontram que, entre as razóes apontadas pelas pequenas e médias empresas brasileiras para não inovar nas edições de 2008 e 2011 da Pintec/IBGE, a principal se refere às condiçôes de mercado, que levam em conta as imperfeiçóes de demanda e/ou da estrutura de oferta. Demais motivos impeditivos à inovaçáo também foram apresentados, porém por um menor número de MPEs e médias empresas: os elevados custos da inovação; os riscos econômicos excessivos; a falta de pessoal qualificado; a escassez de fontes apropriadas de financiamento; entre outros. Uma vez já inovando, os obstáculos concernentes aos problemas internos à empresa, às deficiências técnicas, aos problemas de informação e à estrutura organizacional tornam-se mais significativos para essas firmas.

No que tange à importância e à relevância dos constrangimentos financeiros, tem-se que o acesso aos recursos financeiros e os supostos deficits de capital são as mais comumente citadas e debatidas barreiras à inovação na literatura que aborda as pequenas empresas (Freel, 2000). O problema do acesso ao capital deriva de falhas nos mercados de capitais, como o escasso financiamento ao capital de risco, os procedimentos excessivos, as altas taxas e os prazos restritivos (Zevallos, 2003). O racionamento do crédito por parte das instituições financeiras ocasiona limitado crescimento da MPE e da média empresa e, em certos casos, pode significar 
o encerramento de suas operações (Molina-Ycaza e Sánchez-Riofrío, 2016). A dificuldade de seu acesso deve-se principalmente às elevadas garantias, às altas taxas de juros, aos requisitos excessivos, ao custo e tempo envolvidos nos procedimentos e ao uso do autofinanciamento.

Canepa e Stoneman (2008) identificam que as pequenas empresas podem ser mais fortemente constrangidas por causa da disponibilidade de fundos gerados internamente. Assim, o financiamento de um projeto de inovação de dado tamanho pode ser mais limitado para essas firmas do que para aquelas de grande porte, levando-as frequentemente a aproximarem-se de financiadores externos. Entretanto, os problemas de assimetria de informação e do escopo para o risco moral podem ser mais severos para esse conjunto de empresas do que para as firmas de grande porte, resultando em racionamento de crédito geral ou falha de mercado na provisão de recursos financeiros para as pequenas empresas (Freel, 2000; Hewitt-Dundas, 2006; Canepa e Stoneman, 2008).

Molina-Ycaza e Sánchez-Riofrío (2016) observam que a falta de financiamento limita as tentativas de melhoria a favor do desenvolvimento das competências laborais de micro, pequenas e médias empresas. Da mesma forma, as limitadas capacidades dos trabalhadores reduzem as possibilidades de absorver novos conhecimentos - associados às novas tecnologias. Conforme os autores, a qualificação dos recursos humanos na MPE e média empresa constitui um problema declarado tanto na União Europeia (UE) como na América Latina.

Bosworth (1989) salienta que há ligaçóes diretas entre a intensidade de capital, o nível de tecnologia e a estrutura de habilidades (skills) da empresa. Com o objetivo de desenvolver e crescer, firmas menores enfrentam o problema de aumentar a qualidade e o nível de expertise de sua força de trabalho. Caso contrário, a empresa fica vulnerável diante da mudança nas condições de mercado e dos avanços tecnológicos entre os maiores concorrentes. Entretanto, as pequenas firmas são menos capazes de atrair pessoal de elevada qualidade, ademais de haver tendência para que o gestor-proprietário do pequeno negócio subestime a qualidade de sua mão de obra.

\section{METODOLOGIA}

O governo brasileiro seguiu a tendência internacional de pesquisas de inovação e, influenciado tanto pelo Manual de Frascati (1981) quanto pelo Manual de Oslo (1992), desenvolveu, por meio do IBGE, a Pintec, que teve a primeira edição em $2000 .^{8}$ A metodologia sugerida pela segunda edição do Manual de Oslo foi adotada por essa pesquisa, notadamente aquela proposta na terceira versão do community innovation survey (CIS-3) (Bastos, Rebouças e Bivar, 2003).

8. Silva e Furtado (2017) fazem uma análise, por meio de entrevistas com uma amostra intencional de atores-chave, da gênese da Pintec, mostrando quais foram as motivações para sua realização. 
A Pintec é o principal survey sobre as atividades inovativas das empresas brasileiras - por setor de atividade econômica - e é fonte de informação para cálculo de diversos indicadores sobre o desempenho inovativo (indicadores de resultados i.e., output indicators) e sobre os esforços para empreender atividades inovativas (indicadores de esforço - ou seja, input indicators). A partir do survey da Pintec, é possível apontar os impactos relacionados ao produto (melhorar a qualidade ou ampliar a gama de produtos ofertados), ao mercado (manter ou ampliar a participação da empresa no mercado e abrir novos mercados), ao processo (aumentar a flexibilidade ou a capacidade produtiva e reduzir custos), aos aspectos concernentes ao meio ambiente, à saúde e à segurança, bem como ao enquadramento em regulamentações e normas. Para ilustrar a riqueza de informações disponíveis a partir da Pintec, Cavalcante e De Negri (2011), por exemplo, apresentam os principais indicadores de inovação no Brasil.

\subsection{Base de dados e estratégia de coleta dos dados}

Neste artigo, foram utilizados dados da Pintec/IBGE, abrangendo os resultados das últimas seis ediçóes (2003, 2005, 2008, 2011, 2014 e 2017). Vale salientar que não serão analisadas neste trabalho as respostas da Pintec realizada em 2000, visto que, por tratar-se da primeira pesquisa, contou com o processo de aprendizado das empresas nas suas respostas. De acordo com Rebouças (2005), as empresas passaram a ser mais criteriosas nas respostas após 2000, o que refletiu em reduçóes consideráveis em alguns indicadores, que não necessariamente indicam queda real. Isso aconteceu nas variáveis analisadas neste trabalho; por isso, optou-se em utilizar os dados do survey de 2003 em diante, até sua última edição disponível.

$\mathrm{O}$ acesso às bases da Pintec permite separar as empresas industriais (extrativistas e de transformação) em dois conjuntos: firmas que realizaram processos inovativos e aquelas que não os empreenderam. As primeiras são conhecidas como empresas industriais inovadoras, enquanto as últimas, como empresas industriais não inovadoras. ${ }^{9}$ É exatamente esse o primeiro passo para a construção da base de dados a ser analisada neste artigo.

O grupo de empresas não inovadoras é muito superior ao das inovadoras, conforme pode ser observado na tabela 1. Para fins de exemplificação, tem-se que em 2017 o total de empresas industriais avaliadas na Pintec foi superior a $102 \mathrm{mil}$ empresas, das quais pouco mais de 65 mil não implementaram inovaçóes - ou seja, aproximadamente $64 \%$ das empresas industriais respondentes da pesquisa.

9. De acordo com a Pintec, inovar significa criar - ou aprimorar - produtos e/ou processos novos - para a empresa, não sendo, necessariamente, novo para o mercado de atuação. Ademais, considera-se ainda inovar a implementação de um novo método organizacional nas práticas de negócios da empresa. 
TABELA 1

Universo das empresas industriais, por porte, de acordo com faixa de pessoal ocupado na Pintec

\begin{tabular}{lrrrrrr}
\hline & 2003 & 2005 & 2008 & 2011 & 2014 & 2017 \\
\hline Total de empresas industriais & 84.262 & 91.055 & 100.496 & 116.632 & 117.976 & 102.514 \\
MPEs (até 99 empregados) & 76.322 & 82.336 & 91.220 & 106.384 & 107.729 & 93.509 \\
Média (de 100 a 499 empregados) & 6.576 & 7.182 & 7.616 & 8.289 & 8.278 & 7.269 \\
Grande (mais de 500 empregados) & 1.364 & 1.537 & 1.660 & 1.959 & 1.968 & 1.735 \\
\hline Total de empresas industriais não inovadoras & 53.911 & 58.621 & 59.586 & 72.419 & 71.510 & 65.812 \\
MPEs (até 99 empregados) & 50.134 & 55.449 & 55.123 & 67.290 & 67.146 & 61.660 \\
Média (de 100 a 499 empregados) & 3.442 & 2.890 & 4.036 & 4.313 & 3.726 & 3.618 \\
Grande (mais de 500 empregados) & 335 & 283 & 426 & 816 & 639 & 534 \\
\hline Percentual de empresas industriais não inovadoras & 63,98 & 64,38 & 59,29 & 62,09 & 60,61 & 64,20 \\
Percentual de MPEs industriais não inovadoras & 65,69 & 67,34 & 60,43 & 63,25 & 62,33 & 65,94 \\
Percentual de médias empresas industriais não inovadoras & 52,34 & 40,24 & 52,99 & 52,03 & 45,01 & 49,77 \\
Percentual de grandes empresas industriais não inovadoras & 24,56 & 18,41 & 25,66 & 41,65 & 32,47 & 30,78 \\
\hline
\end{tabular}

Fonte: Pintec/IBGE.

Elaboração dos autores.

O passo seguinte para a construção da base de dados é classificar as empresas de acordo com seu porte nos distintos grupos empresas industriais inovadoras e empresas industriais não inovadoras. Vale lembrar que não existe apenas uma maneira possível de classificar as empresas de acordo com seu tamanho. Várias proxies podem ser utilizadas para a classificação das empresas nas categorias micro, pequena, média e grande. Geralmente, utiliza-se da receita bruta anual das empresas ou do número de empregados. Mesmo assim, é possível encontrar diferentes classificaçóes, uma vez que os limites que separam uma categoria da outra podem variar. Por exemplo, de acordo com dispositivo legal de 2006 (Lei Complementar - LC no 123), microempresa é aquela que aufere, em cada ano-calendário, receita bruta igual ou inferior a $\mathrm{R} \$ 360$ mil, enquanto a empresa de pequeno porte obtém receita bruta superior a $\mathrm{R} \$ 360$ mil e igual ou inferior a $\mathrm{R} \$ 4.800$ mil (Brasil, 2006). Acima desse valor, não há definição legal que trate da diferença entre média e grande empresa.

Por sua vez, de acordo com IBGE (2012), são consideradas microempresas aquelas com até nove pessoas ocupadas; empresas pequenas são as que possuem de 10 a 49 pessoas; as empresas médias possuem de 50 a 249 pessoas; e as empresas grandes contêm 250 ou mais pessoas ocupadas. No entanto, de acordo com Sebrae (2013), há separação entre setores econômicos distintos (indústria versus comércio e serviços) na classificação das empresas pelo porte. Assim sendo, uma microempresa industrial possui até dezenove empregados, uma pequena empresa 
de 20 a 99, uma média empresa de 100 a 499 e uma grande empresa acima de 500 empregados (Sebrae, 2013). Neste artigo, utiliza-se a classificação proposta pelo Sebrae (2013) e opta-se em somar as MPEs em apenas uma categoria. Desse modo, há os seguintes portes possíveis, por faixa de pessoal ocupado:

- micro e pequenas empresas (até 99 empregados);

- médias empresas (de 100 a 499); e

- grandes empresas (mais de 500 empregados).

Os dados da tabela 1 apresentam os quantitativos das empresas industriais que responderam ao survey de inovação em cada ano por faixa de pessoal ocupado. Pode-se notar que, em todos os anos da Pintec, as MPEs representam mais de $90 \%$ das firmas que participaram da pesquisa; em 2017, por exemplo, das mais de 102 mil empresas, pouco mais de $91 \%$ são empresas industriais com até 99 empregados ocupados.

Tendo sido definidos os grupos de empresas industriais inovadoras e não inovadoras e tendo classificado em cada um desses grupos as empresas por porte, passa-se ao terceiro passo para a construção da base de dados. É possível avaliar quais foram os fatores impeditivos que as firmas industriais não inovadoras tiveram para não terem inovado e quais foram as dificuldades que as empresas industriais inovadoras enfrentaram durante o processo inovativo.

Ao separar as empresas industriais inovadoras das não inovadoras, o survey de inovação consegue captar a percepção do que dificultou a inovação do primeiro grupo de empresas e a percepção do que impediu as inovaçóes do segundo grupo, conforme apresentado pela figura 1 .

FIGURA 1

Fluxograma baseado no survey de inovação

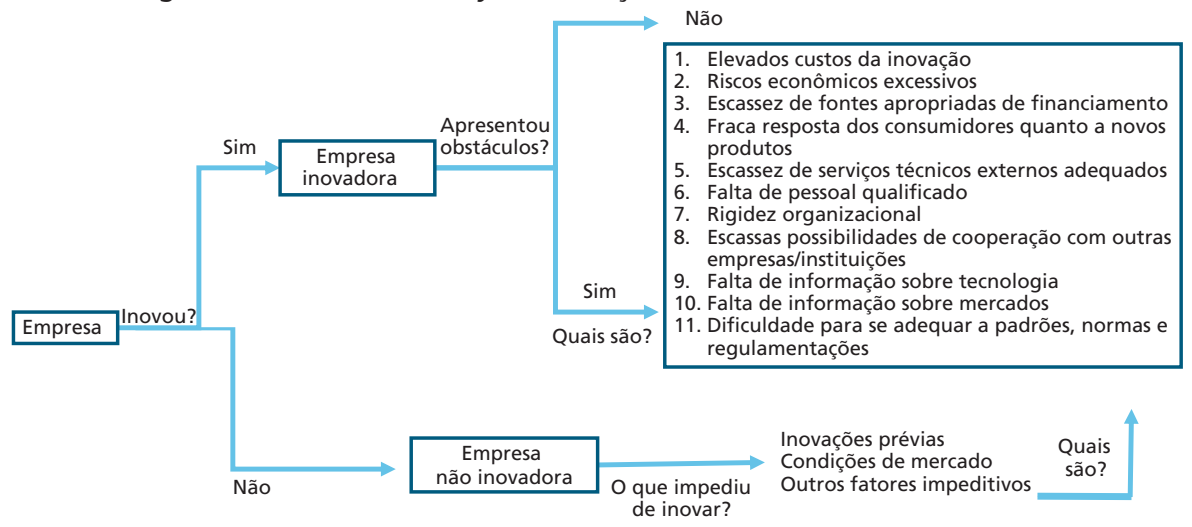


Os obstáculos apresentados pela Pintec foram agrupados em categorias para fins de simplificação analítica, conforme apresentados no quadro 1:

- obstáculos econômicos e institucionais;

- obstáculos organizacionais; e

- obstáculos informacionais e tecnológicos.

QUADRO 1

Outros fatores impeditivos ao processo de inovação

\begin{tabular}{|l|l|}
\hline Elevados custos de inovação & \\
\cline { 1 - 1 } Riscos econômicos excessivos & \multirow{2}{*}{$\begin{array}{l}\text { Obstáculos econômicos } \\
\text { e institucionais }\end{array}$} \\
\cline { 1 - 1 } Escassez de fontes apropriadas de financiamento & \\
\cline { 1 - 2 } Fraca resposta dos consumidores quanto a novos produtos & \multirow{2}{*}{ Obstáculos } \\
Escassez de serviços técnicos externos adequados & organizacionais \\
\hline Falta de pessoal qualificado & $\begin{array}{l}\text { Obstáculos informacionais } \\
\text { Rigidez organizacional }\end{array}$ \\
\hline Escassas possibilidades de cooperação com outras empresas/instituições
\end{tabular}

Fonte: IBGE (2016).

Elaboração dos autores.

Por fim, cabe destacar que as empresas respondentes da Pintec podem atribuir diferentes graus de importância a cada fator que afeta o processo inovativo, variando de baixo, médio e alto. Optou-se neste trabalho por analisar somente as respostas de grau de importância alto, na busca de inferir os obstáculos realmente relevantes para as empresas.

\subsection{Análise dos dados}

Uma vez construída a base de dados das empresas industriais - inovadoras ou não -, por porte e que atribuiu grau de importância alto aos obstáculos à inovação, passa-se à estratégia de análise dos dados.

Optou-se, portanto, em realizar uma análise estatística descritiva, que possibilita organizar, resumir e descrever os aspectos importantes do conjunto de características observadas (Reis e Reis, 2002) e permite, dessa forma, que se tenha uma visão global das suas variações, comparando-se dois conjuntos (empresas inovadoras e não inovadoras) e seus subconjuntos (MPEs, médias e grandes empresas).

Desse modo, os dados são organizados por meio de tabelas, figuras e também medidas de síntese - como porcentagens -, as quais apresentam elementos 
para corroborar a proposição inicial do artigo. No entanto, vale ressaltar que, ao se condensar os dados, se perde informação (Reis e Reis, 2002), uma vez que não há as observaçóes de cada empresa individual e infelizmente não é possível fazer análises sobre relaçôes causais entre tamanho das empresas e obstáculos à inovação, devido à falta de acesso aos microdados, o que impossibilita análises econométricas.

Na próxima seçẫo, são analisados quais são os fatores percebidos pelas empresas industriais não inovadoras, divididas por porte, que impediram a implementação de inovaçóes em cada período. São também estudados os fatores percebidos pelas empresas industriais inovadoras, por porte, no tocante a dificuldades em implementar inovaçóes no Brasil.

\section{PROBLEMAS E OBSTÁCULOS À INOVAÇÃO NO BRASIL SEGUNDO O PORTE DA FIRMA}

\subsection{Empresas industriais não inovadoras: por que não inovam?}

A Pintec indica três razões pelas quais as empresas industriais não inovadoras não desenvolveram e nem implementaram inovaçóes, conforme foi representado na figura 1:

- inovaçóes prévias;

- condições de mercado; e

- outros fatores impeditivos.

Rapini (2013) havia identificado, com base dos dados da Pintec, que, entre os motivos atribuídos pelas empresas não inovadoras que desestimularam a inovação, o principal é as condiçôes do mercado. Sua análise cobriu os dados de 2000 a 2005. Em uma perspectiva de tempo maior, levando-se em conta as informações de 2003 a 2014, tem-se que o principal obstáculo para as empresas industriais não inovadoras continua sendo as condiçôes de mercado (Rapini, 2013; Rapini, Chiarini e Bittencourt, 2017).

Do ponto de vista econômico, condiçôes (desfavoráveis) de mercado são geradas por deficiência de demanda - seja esta agregada e/ou setorial - ou por insuficiência da estrutura de oferta (concorrencial ou capacidade instalada), que podem desestimular a inovação (Rapini, Chiarini e Bittencourt, 2017). Em 2003, das pouco mais de 84 mil empresas industriais que responderam à Pintec, 63,98\% não desenvolveram nem implementaram inovaçóes. Destas, 65,39\% apontaram como a principal razão para não terem inovado as condiçóes de mercado desfavoráveis. Por sua vez, em 2017, das 102.514 empresas industriais presentes na pesquisa, $64,20 \%$ são firmas náo inovadoras, sendo que $61,56 \%$ destas não desenvolveram e nem implementaram inovaçóes devido às condiçóes de mercado (gráfico A.2 e tabela A.2, no apêndice). 
GRÁFICO 1

Empresas industriais que não desenvolveram e nem implementaram inovações, de acordo com os motivos, e empresas que não implementaram inovações e sem projetos - Brasil (Em \%)

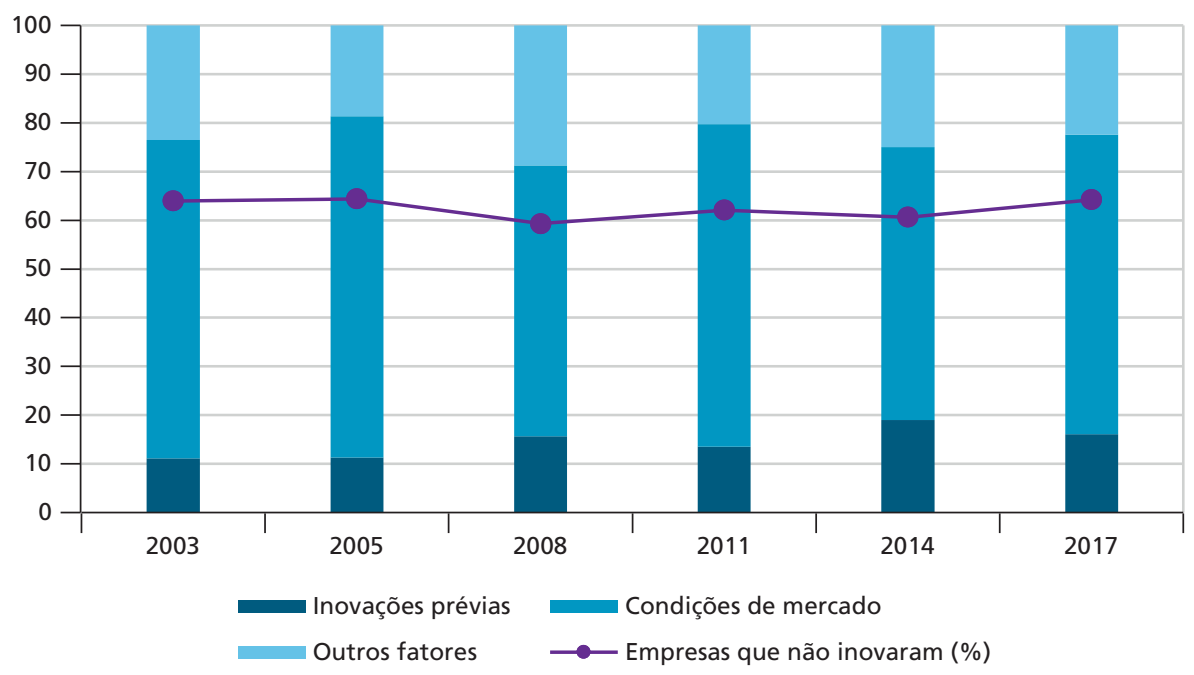

Fonte: Pintec/IBGE. Disponível em: <https://is.gd//niWlm>.

Elaboração dos autores.

Cabe destacar que o porte das empresas industriais (MPEs, médias e empresas grandes) parece não afetar a percepção de que as condiçôes de mercado são obstáculos predominantes. Para todos os portes de empresa as condiçóes de mercado, em termos percentuais, foram superiores a 50\%, exceção para 2014 quando para médias e grandes empresas as condiçôes de mercado ficaram abaixo dos $50 \%$. Porém, já na última pesquisa essa razão volta a crescer para todos os portes (tabela 2).

\section{TABELA 2}

Distribuição das razões porque as empresas não implementaram inovações, segundo tamanho e total de empresas que não inovaram

\begin{tabular}{llllllll}
\hline & & 2003 & 2005 & 2008 & 2011 & 2014 & 2017 \\
\hline & Inovações prévias & 10,69 & 10,91 & 15,29 & 13,02 & 18,58 & 15,85 \\
MPEs - até 99 empregados (\%) & Condições de mercado & 65,34 & 70,44 & 55,37 & 66,66 & 56,50 & 61,92 \\
& Outros fatores & 23,98 & 18,65 & 29,34 & 20,31 & 24,92 & 22,23 \\
\hline & Inovações prévias & 15,84 & 17,66 & 19,90 & 19,62 & 24,68 & 19,22 \\
Empresas industriais médias - & Condições de mercado & 66,87 & 64,14 & 58,63 & 59,93 & 49,22 & 56,41 \\
de 100 a 499 empregados (\%) & Outros fatores & 17,29 & 18,20 & 21,47 & 20,45 & 26,10 & 24,36 \\
\hline & & & & & & & (Continua)
\end{tabular}




\begin{tabular}{llrrrrrr}
\hline (Continuação) & & & & & \\
\hline & & 2003 & 2005 & 2008 & 2011 & 2014 & 2017 \\
\hline $\begin{array}{l}\text { Empresas industriais grandes - } \\
\text { acima de 500 empregados (\%) }\end{array}$ & Condiçõ̃es de mercado & 58,45 & 60,11 & 56,28 & 56,61 & 46,65 & 54,88 \\
& Outros fatores & 17,20 & 19,52 & 21,24 & 19,99 & 26,61 & 26,09 \\
\hline & PMEs & 50.134 & 55.449 & 55.123 & 67.290 & 67.146 & 61.660 \\
Total de empresas industriais & Média & 3.442 & 2.890 & 4.036 & 4.313 & 3.726 & 6.618 \\
$\begin{array}{l}\text { não inovadoras } \\
\text { (valores absolutos) }\end{array}$ & Grande & 335 & 283 & 426 & 816 & 639 & 534 \\
& Total (valor absoluto) & 53.911 & 58.621 & 59.586 & $\mathbf{7 2 . 4 1 9}$ & $\mathbf{7 1 . 5 1 0}$ & $\mathbf{6 5 . 8 1 2}$ \\
\hline $\begin{array}{l}\text { Total de empresas industriais que responderam à } \\
\text { Pintec (valor absoluto) }\end{array}$ & & $\mathbf{8 4 . 2 6 2}$ & $\mathbf{9 1 . 0 5 5}$ & $\mathbf{1 0 0 . 4 9 6}$ & $\mathbf{1 1 6 . 6 3 2}$ & $\mathbf{1 1 7 . 9 7 6}$ & $\mathbf{1 0 2 . 5 1 4}$
\end{tabular}

Fonte: Pintec/IBGE. Disponivel em: <https://is.gd//niWlm>.

Elaboração dos autores.

Apesar de as condiçóes de mercado serem o principal fator apontado pelas empresas não inovadoras, há outros que a Pintec capta: inovaçôes prévias e outros fatores. Estes últimos são apresentados também na tabela 2; na tabela 3, são indicados os percentuais das empresas não inovadoras que atribuíram grau de importância alta a outros fatores limitadores do processo inovativo.

TABELA 3

Distribuição dos obstáculos de grau de importância alto apontados pelas empresas industriais não inovadoras que impedem o processo inovativo

(Em \%)

\begin{tabular}{|c|c|c|c|c|c|c|c|}
\hline \multirow{2}{*}{ Tipos de obstáculos } & \multirow{2}{*}{ Obstáculos } & \multicolumn{6}{|c|}{ Empresas industriais não inovadoras } \\
\hline & & 2003 & 2005 & 2008 & 2011 & 2014 & 2017 \\
\hline \multirow{5}{*}{$\begin{array}{l}\text { Econômicos e } \\
\text { institucionais }\end{array}$} & Elevados custos da inovação & 71,04 & 66,86 & 58,08 & 56,13 & 58,50 & 59,85 \\
\hline & Riscos econômicos excessivos & 58,39 & 51,34 & 49,19 & 43,59 & 50,39 & 59,43 \\
\hline & $\begin{array}{l}\text { Escassez de fontes apropriadas de finan- } \\
\text { ciamento }\end{array}$ & 45,68 & 50,76 & 39,69 & 38,23 & 41,85 & 42,32 \\
\hline & $\begin{array}{l}\text { Fraca resposta dos consumidores quanto a } \\
\text { novos produtos }\end{array}$ & 7,89 & 6,96 & 10,00 & 10,17 & 18,16 & 13,42 \\
\hline & $\begin{array}{l}\text { Escassez de serviços técnicos externos } \\
\text { adequados }\end{array}$ & 8,09 & 12,53 & 10,64 & 18,72 & 19,10 & 17,26 \\
\hline \multirow{3}{*}{ Organizacionais } & Falta de pessoal qualificado & 18,66 & 15,50 & 19,55 & 40,71 & 30,53 & 26,38 \\
\hline & Rigidez organizacional & 6,40 & 6,32 & 6,67 & 13,39 & 21,76 & 15,52 \\
\hline & $\begin{array}{l}\text { Escassas possibilidades de cooperação com } \\
\text { outras empresas/instituições }\end{array}$ & 11,85 & 14,14 & 17,56 & 12,63 & 20,11 & 21,49 \\
\hline \multirow{3}{*}{$\begin{array}{l}\text { Informacionais e } \\
\text { tecnológicos }\end{array}$} & Falta de informação sobre tecnologia & 8,86 & 10,94 & 8,62 & 13,47 & 16,88 & 13,49 \\
\hline & Falta de informação sobre mercados & 8,01 & 7,43 & 6,69 & 10,14 & 12,42 & 12,91 \\
\hline & $\begin{array}{l}\text { Dificuldade para adequar-se a padrões, } \\
\text { normas e regulamentações }\end{array}$ & 15,56 & 15,65 & 12,93 & 15,77 & 22,77 & 26,40 \\
\hline
\end{tabular}

Fonte: Pintec/IBGE. Disponível em: <https://is.gd/lniWlm>.

Elaboração dos autores. 


\subsubsection{Outros fatores: obstáculos econômicos e institucionais}

Para as empresas não inovadoras, entre os outros fatores impeditivos ao processo de inovação, os obstáculos econômicos e institucionais são os mais citados. O principal destes são os elevados custos envolvidos nos processos inovativos, os quais, por exemplo, se relacionam aos gastos diretos com atividades de pesquisa e desenvolvimento ( $\mathrm{P} \& \mathrm{D})$, mão de obra altamente qualificada, os custos circunscritos ao risco técnico/tecnológico, bem como a inserção da inovação no mercado (risco comercial).

Por exemplo, em 2003, 71,04\% das empresas que não inovaram atribuíram alto grau de importância para os elevados custos da inovação. Cabe destacar que existe um movimento no sentido de reduzir a importância dos elevados custos da inovação como fator impeditivo das empresas industriais que não inovaram até 2014; depois parece que houve sinais de reversão a essa tendência (tabela 3). Em 2017, das mais de 65 mil empresas não inovadoras, 14.730 deram algum grau de importância aos obstáculos à inovação (taxa de resposta de 22,38\%), das quais 59,85\% atribuíram grau de importância alto para os elevados custos da inovação. A relativa redução de importância desse obstáculo, de 2003 a 2014, ocorre tanto para MPEs quanto para médias empresas, as quais passaram a dar menos importância aos elevados custos da inovação como obstáculo ao processo inovativo; no entanto, para grandes empresas não inovadoras, isso não ocorre (de 43,69\%, em 2003, aumentou para 57,81\%, em 2014, e 54,01\%, em 2017).

Por sua vez, os riscos econômicos excessivos são apresentados como o segundo obstáculo mais importante para as empresas industriais não inovadoras - independentemente do porte; conferir tabela A.1, no apêndice). Cabe destacar, no entanto, que apenas para o grupo de grandes empresas não inovadoras, em 2014 e em 2017, os riscos econômicos excessivos ultrapassam em importância os elevados custos de inovação, passando a ser percebidos como o principal obstáculo (figura 2 e tabela A.1, no apêndice).

As empresas industriais não inovadoras também apontaram a escassez de fontes apropriadas de financiamento como fator que impede os processos inovativos. Em 2003, 45,68\% destas mencionaram ser este um obstáculo de grau de importância alta, ao passo que em 2017 passaram a representar 42,32\% (tabela 3). No entanto, ao se analisar os dados de acordo com o tamanho da empresa, pode-se notar que a escassez de fontes apropriadas de financiamento tem peso maior para as MPEs não inovadoras vis-à-vis às médias e grandes empresas. Enquanto em 2017, 42,86\% das MPEs não inovadoras apontaram como obstáculo de grau de importância alto a escassez de financiamento, nesse período, 33,58\% e 44,56\% das empresas médias e grandes deram o mesmo grau de importância. 
Os outros dois fatores relacionados aos obstáculos econômicos e institucionais são: fraca resposta dos consumidores quanto a novos produtos e escassez de serviços técnicos externos adequados. Ambos os obstáculos são apontados de forma crescente de 2003 a 2014 pelas empresas industriais não inovadoras (tabela 3). Entretanto, tanto a fraca resposta dos consumidores em relação a novos produtos quanto a escassez de serviços técnicos externos adequados são afetadas pelo tamanho das firmas: as empresas mais sensíveis são as MPEs e as médias empresas não inovadoras (figura 2 e tabela A.1, no apêndice). Cabe salientar que 2017 parece ser um período de inflexão: as grandes firmas não inovadoras aumentaram o grau de importância à fraca demanda dos consumidores.

\subsubsection{Outros fatores: obstáculos organizacionais}

A falta de pessoal qualificado é um importante impeditivo para processos inovativos, conforme apresentado por Rapini, Chiarini e Bittencourt (2017). Para os autores, a percepção das empresas brasileiras sobre a falta de indivíduos qualificados para o processo de inovação é um elemento novo, verificado exatamente no momento em que aumentou substancialmente o suporte ao processo de inovação por intermédio de políticas de inovação no país, desde 2004.

De fato, no caso das empresas industriais não inovadoras, em 2003, 18,66\% informaram que a falta de pessoal qualificado é um obstáculo de grau de importância alta, enquanto em 2014 passaram a representar 30,53\% (tabela 3). Entretanto, as MPEs não inovadoras são as que mais deram importância em termos percentuais à falta de pessoal qualificado em relação às médias e grandes empresas. Das MPEs, $31,48 \%$ apontaram-na como elemento impeditivo do processo inovativo; entre as médias, $17,13 \%$ indicaram esse fator como impeditivo e entre as grandes, 13,40\%, em 2014 (figura 2 e tabela A.1, no apêndice). Interessante destacar que para os três grupos de empresas há mudança nessa tendência em 2017, quando a falta de pessoal qualificado tem importância relativa menor como obstáculo à inovação.

Os demais obstáculos organizacionais apresentados pelas empresas não inovadoras (a rigidez organizacional e as escassas possibilidades de cooperação com outras empresas/instituiçôes) tiveram percepção crescente como fatores impeditivos à inovação até 2014. Vale destacar que a rigidez organizacional afeta de forma diferenciada as empresas de acordo com seu porte; em 2017, por exemplo, 15,97\% das MPEs não inovadoras apontam-na como relevante, enquanto apenas $9,78 \%$ das médias e $7,71 \%$ das grandes empresas indicaram tal fator como importante. Igualmente, as escassas possibilidades de cooperação são relativamente mais importantes para as MPEs que para as médias e grandes empresas não inovadoras (figura 2 e tabela A.1, no apêndice). 


\subsubsection{Outros fatores: obstáculos informacionais e tecnológicos}

Entre os obstáculos técnicos que impedem o processo inovativo, as empresas industriais não inovadoras apresentam a dificuldade para se adequar a padröes, normas e regulamentaçóes como o mais importante (26,40\% destas em 2017$)$ seguida da falta de informação sobre tecnologias (13,49\%) e falta de informação sobre mercados $(12,91 \%)$ (tabela 2).

Ao analisarem-se as empresas não inovadoras por porte, verifica-se que a dificuldade para se adequar a padrôes, normas e regulamentaçôes é um fator impeditivo ao processo inovativo menos importante para médias e grandes empresas, em comparação com as MPEs para todas as ediçóes da Pintec. Isso pode ser dito sobre os demais obstáculos técnicos e tecnológicos (figura 2 e tabela A.1, no apêndice). As MPEs possuem mais dificuldades para acessar as informaçôes sobre as tecnologias disponiveis e sobre os mercados do que as médias e grandes empresas.

FIGURA 2

Grau de importância alta por obstáculos apontados pelas empresas industriais não inovadoras, por porte (2017)

(Em \%)

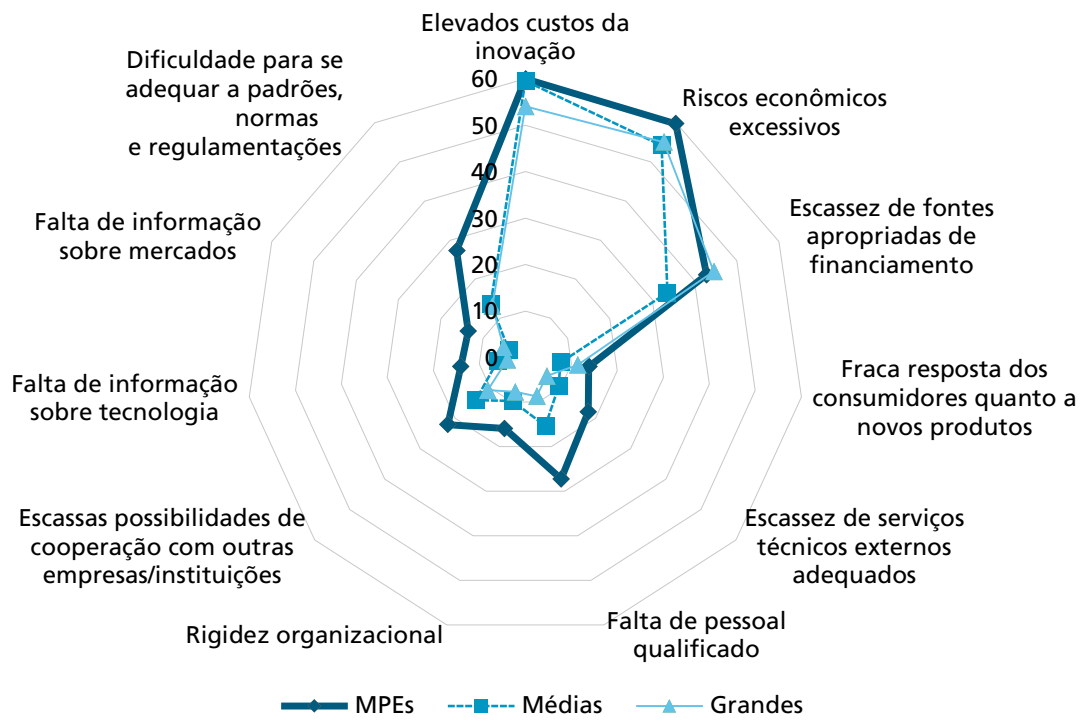

Fonte: Pintec/IBGE. Disponível em: <https://is.gd//niWlm>.

Elaboração dos autores. 


\subsection{Empresas industriais inovadoras: o que dificulta o processo inovativo?}

No que se refere às empresas industriais inovadoras, a Pintec capta os principais fatores que dificultam seu processo inovativo. Estes estão presentes na tabela A.2 (apêndice) e são os mesmos fatores que as empresas não inovadoras destacam como outros fatores impeditivos. $\mathrm{Na}$ tabela 4, são expressos os percentuais das empresas industriais inovadoras que atribuíram a esses fatores impeditivos de importância alta.

TABELA 4

Distribuição dos obstáculos de grau de importância alto apontados pelas empresas industriais inovadoras que impedem o processo inovativo

(Em \%)

\begin{tabular}{|c|c|c|c|c|c|c|c|}
\hline \multirow{2}{*}{ Tipos de obstáculos } & \multirow{2}{*}{ Obstáculos } & \multicolumn{6}{|c|}{ Empresas industriais "inovadoras" } \\
\hline & & 2003 & 2005 & 2008 & 2011 & 2014 & 2017 \\
\hline \multirow{5}{*}{$\begin{array}{l}\text { Econômico e } \\
\text { institucional }\end{array}$} & Elevados custos da inovação & 54,90 & 54,91 & 47,30 & 51,68 & 52,77 & 51,15 \\
\hline & Riscos econômicos excessivos & 52,84 & 49,04 & 39,28 & 41,50 & 53,36 & 54,89 \\
\hline & $\begin{array}{l}\text { Escassez de fontes apropriadas de } \\
\text { financiamento }\end{array}$ & 45,99 & 46,71 & 38,26 & 42,06 & 46,52 & 46,96 \\
\hline & $\begin{array}{l}\text { Fraca resposta dos consumidores quanto a } \\
\text { novos produtos }\end{array}$ & 9,66 & 11,52 & 10,32 & 12,16 & 12,33 & 13,87 \\
\hline & $\begin{array}{l}\text { Escassez de serviços técnicos externos } \\
\text { adequados }\end{array}$ & 11,52 & 15,90 & 15,28 & 24,40 & 15,14 & 21,90 \\
\hline \multirow{3}{*}{ Organizacionais } & Falta de pessoal qualificado & 23,93 & 22,10 & 36,11 & 49,52 & 32,18 & 33,46 \\
\hline & Rigidez organizacional & 5,84 & 10,32 & 14,33 & 14,65 & 18,18 & 13,68 \\
\hline & $\begin{array}{l}\text { Escassas possibilidades de cooperação com } \\
\text { outras empresas/instituições }\end{array}$ & 16,56 & 13,80 & 16,22 & 20,93 & 21,22 & 16,58 \\
\hline \multirow{3}{*}{ Técnicos e tecnológicos } & Falta de informação sobre tecnologia & 15,23 & 12,07 & 13,89 & 16,14 & 16,65 & 13,18 \\
\hline & Falta de informação sobre mercados & 12,66 & 9,92 & 8,99 & 13,46 & 13,19 & 9,55 \\
\hline & $\begin{array}{l}\text { Dificuldade para se adequar a padrões, } \\
\text { normas e regulamentações }\end{array}$ & 17,73 & 18,69 & 14,03 & 19,53 & 19,76 & 17,42 \\
\hline
\end{tabular}

Fonte: Pintec/IBGE. Disponível em: <https://is.gd//niWlm>.

Elaboração dos autores.

Nota-se que praticamente o mesmo resultado encontrado em relaçáo às empresas industriais não inovadoras é observado no que concerne às inovadoras. Em outras palavras, tem-se que os riscos econômicos excessivos e os elevados custos da inovação são os principais obstáculos econômicos e institucionais apresentados, indiferentemente do porte da empresa inovadora. A escassez de fontes apropriadas de financiamento também é apontada como obstáculo significativo pelas empresas inovadoras; porém, as MPEs inovadoras são mais afetadas do que as demais. Finalmente, as empresas inovadoras também possuem uma percepção crescente de que a débil resposta dos consumidores no que se refere a novos produtos e a carência de serviços técnicos externos satisfatórios são obstáculos cada vez mais considerados. 


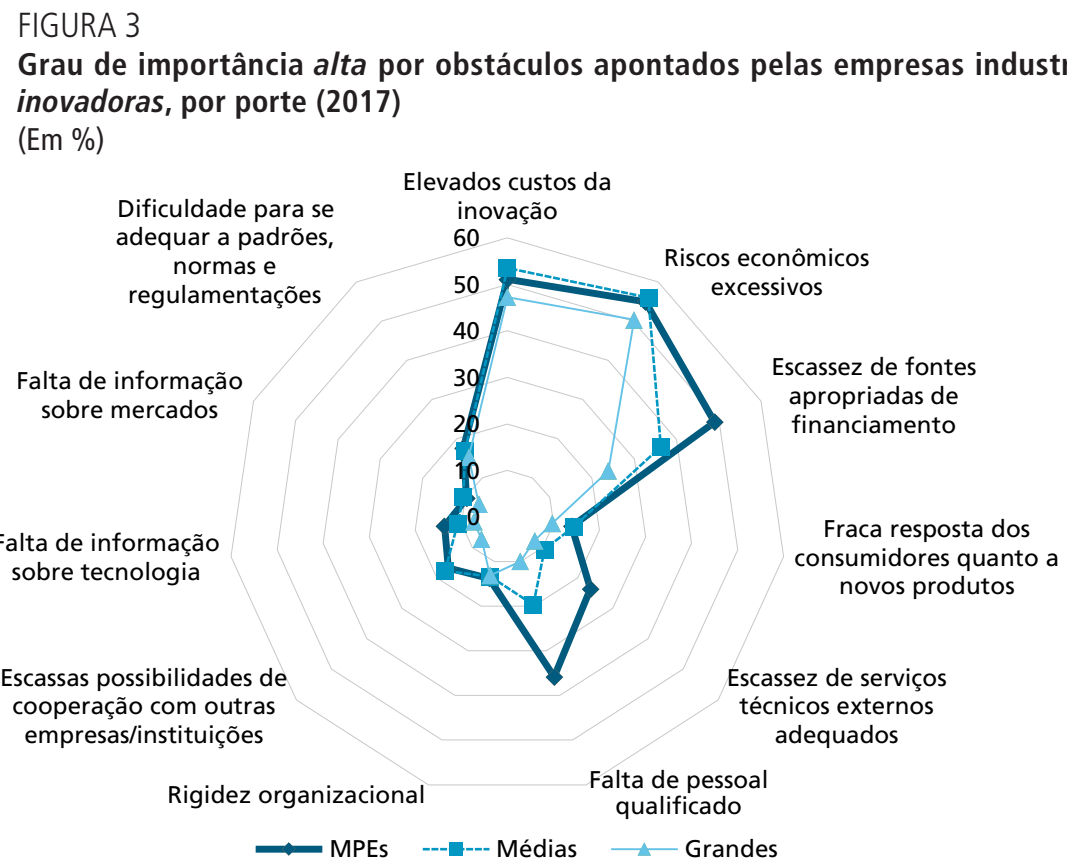

Fonte: Pintec/IBGE. Disponivel em: <https://is.gd//niWlm>.

Elaboração dos autores.

No que se refere aos obstáculos organizacionais, a falta de pessoal qualificado, a rigidez organizacional e as escassas possibilidades de cooperação com outras empresas/instituiçôes têm sido apontadas pelas empresas industriais inovadoras como obstáculos de importância alta à inovação. No entanto, são obstáculos mais significativos para as MPEs inovadoras do que para as médias e grandes empresas inovadoras.

Finalmente, no que se refere aos obstáculos informacionais e tecnológicos, as empresas industriais inovadoras têm praticamente a mesma percepção que as não inovadoras. Ademais, os obstáculos informacionais e tecnológicos são mais sensíveis às MPEs do que as médias e grandes inovadoras (figura 3 e tabela A.1, no apêndice).

É possível concluir, portanto, que os fatores econômicos e institucionais, organizacionais e informacionais e tecnológicos afetam praticamente da mesma forma as empresas industriais inovadoras e as não inovadoras e que as MPEs - inovadoras ou não - são mais afetadas por todos os fatores do que as grandes empresas. 


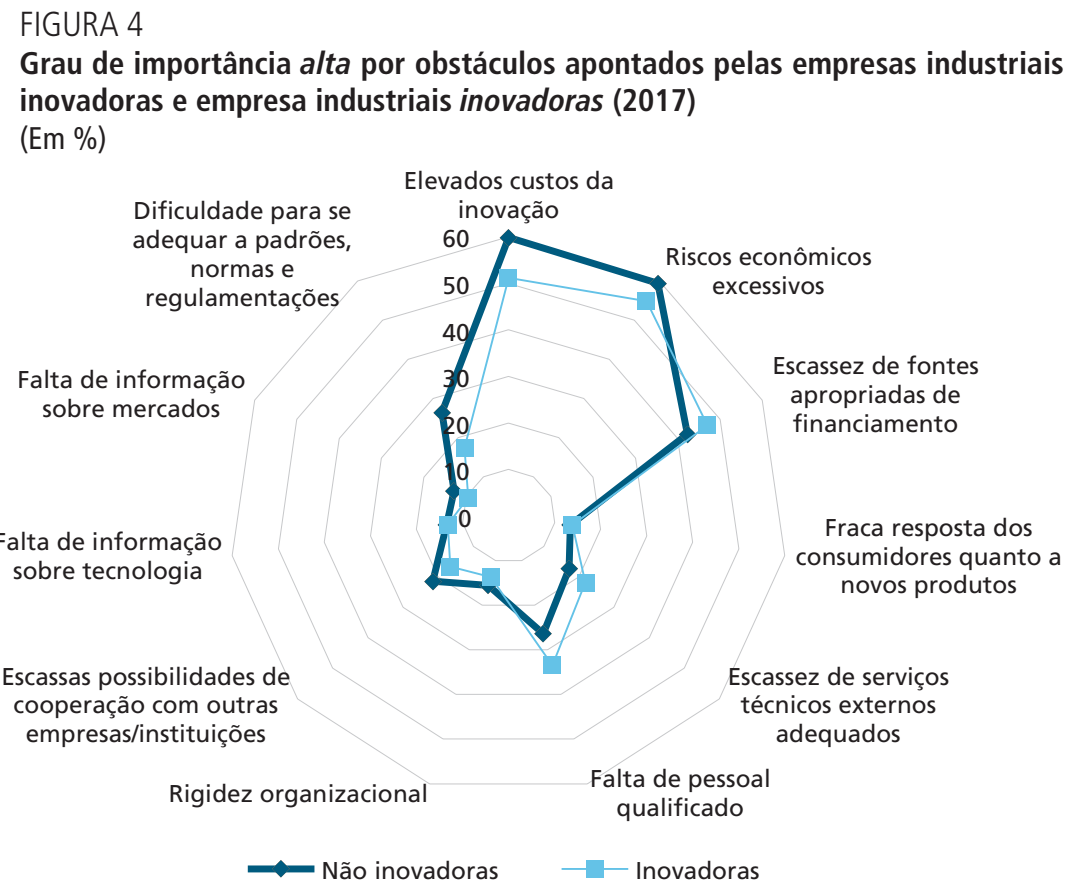

Fonte: Pintec//BGE. Disponivel em: <https://is.gd//niWlm>.

Elaboração dos autores.

\section{CONSIDERAÇÕES FINAIS}

Há um cenário estrutural do ponto de vista macroeconômico que desestimula os investimentos em atividades inovativas industriais no Brasil. De acordo com Cano (2012), Carvalho (2018) e Gala e Roncaglia (2020), a política de câmbio demasiadamente valorizado, aliada a práticas de juros reais elevados, desincentivou o empresário capitalista a realizar investimentos de longo prazo, como aqueles em atividades inovativas. Esse cenário adverso reforça o processo de desindustrializaçáo brasileiro e a perda de elos das cadeias produtivas (Morceiro e Guilhoto, 2020), o qual é intensificado por crises político-econômicas conjunturais -iniciadas a partir de 2013 e que ganharam novas configuraçóes a partir de 2016.

Todo esse cenário impede - ou, na melhor das hipóteses, dificulta - a expansão da população de empresas inovadoras no país. De fato, o percentual de empresas industriais não inovadoras tem se mantido elevado nos últimos anos, e, na edição de 2017 da Pintec, nota-se um crescimento em relação às edições de 2008, 2011 e 2014, o que é significativo se recordado que a amostra da pesquisa é enviesada para empresas potenciais inovadoras. 
Ao analisar as empresas por porte, foi possível verificar que o grupo de empresas industriais que possui o maior percentual de empresas não inovadoras é aquele formado pelas MPEs em todas as ediçóes da Pintec. No entanto, as grandes empresas industriais (acima de 500 funcionários empregados), que possuíam um percentual relativamente pequeno de empresas não inovadoras em 2003 (24,56\%), aumentaram para $32,78 \%$ - em 2017 - e o principal motivo impeditivo apontado por estas foram as condiçôes adversas de mercado, as quais refletem, além do cenário estrutural apresentado, as percepçôes negativas em relação as crises conjunturais.

Outros fatores impeditivos do processo inovativo foram igualmente apontados pelas empresas não inovadoras independente do seu porte. Uma análise descritiva desses fatores permitiu verificar que os principais fazem parte de um conjunto de elementos de natureza econômica e institucional. Indiferentemente dos portes das empresas não inovadora, o principal desses obstáculos, para todos os anos analisados, é o elevado custo de inovação, seguido dos riscos econômicos e da escassez de fontes apropriadas de financiamento.

Os dados também permitem afirmar que os obstáculos organizacionais e os informacionais e tecnológicos afetam as empresas de acordo com seu porte. Por exemplo, a falta de pessoal qualificado afeta mais as MPEs do que as grandes empresas. Isso também pode ser dito sobre a rigidez organizacional, as escassas possibilidades de cooperação com outras empresas, a falta de informação sobre tecnologia, a falta de informação sobre mercados e a dificuldade para se adequar a padróes, normais e regulamentaçôes.

Finalmente, a análise descritiva dos dados permite constatar que as empresas inovadoras apontam as mesmas dificuldades que as não inovadoras para levar a cabo seus processos inovativos. Igualmente, ficou patente que o porte das empresas inovadoras afeta sua percepçáo quanto aos obstáculos enfrentados para o desenvolvimento de novos produtos e processos.

Portanto, a análise proposta neste trabalho permite constatar que os obstáculos econômicos e institucionais, informacionais e tecnológicos e organizacionais são fatores que dificultam e impedem processos inovativos de forma semelhante tanto em empresas inovadoras quanto não inovadoras; no entanto, seu porte importa. Isto é, quanto maior o tamanho da empresa - cuja proxy é o número de empregados -, menos obstáculos esta enfrenta para inovar vis-à-vis as MPEs e as médias.

Vários instrumentos e programas foram criados nos últimos anos pelos governos federal e estaduais, com o objetivo de reduzir vários dos obstáculos organizacionais e informacionais e tecnológicos enfrentados pelas empresas inovadoras (Lei do Bem, Lei da Inovação e Lei de Incentivo à Pesquisa); no entanto, os problemas ainda persistem, e as MPEs também se mantêm como as mais afetadas. As políticas de fomento à inovação, ainda que tenham se ampliado de forma considerável nas 
últimas décadas e que estejam sendo importantes para o fomento às MPEs (Avellar e Botelho, 2015), não fazem clara distinção entre empresas que já inovam e que deveriam aumentar seu esforço inovador daquelas que ainda não inovam, mas que poderiam começar a inovar. Ainda que os obstáculos enfrentados por esse conjunto distinto de empresas sejam semelhantes, as formas de superá-los são distintas, merecendo maior atenção por parte das instituiçôes de fomento, como a Financiadora de Estudos e Projetos (Finep), as fundações de apoio à pesquisa (FAPs), o Banco Nacional de Desenvolvimento Econômico e Social (BNDES) e a Empresa Brasileira de Pesquisa e Inovação Industrial (Embrapii). É preciso, por exemplo, que políticas públicas pró-inovação incorporem a necessidade de elevação da capacidade de absorção de MPEs e médias empresas. Isso pode ser implementado pelas vias de estímulos: i) à contratação e à fixação de recursos humanos qualificados (graduados e, particularmente, pós-graduados) nas firmas; ii) aos esforços de P\&D por meio de instrumentos voltados às particularidades dessas firmas (Oliveira, 2019); e iii) a propostas para que absorvam a chamada cultura da inovação e do empreendedorismo em suas estruturas organizacionais, a fim de que passem a manifestar os impactos positivos de programas de gestão tecnológica e da inovação.

Alguns trabalhos já evidenciaram que empresas "aprendem" a captar recursos públicos (Cannan, 2016) e o fazem de forma sistemática ao longo dos anos, inclusive de distintas agências de fomento (Silva, Rapini e Schultz, 2010). Portanto, as restriçóes de financiamento para quem não inova estâo relacionadas à dificuldade em conseguir captar os recursos, o que é distinto de restriçôes de financiamento para quem inova, que podem estar associadas a recursos de diferentes modalidades ou à necessidade de recursos em maior montante nas distintas etapas do processo de inovação.

Finalmente, vale lembrar que inovar é uma atividade complexa e envolve uma multiplicidade de atores e interaçóes. Esse processo pode ser afetado em diversas etapas por diferentes barreiras, algumas das quais podem ser insuperáveis e interrompem por completo o processo inovativo. Tais barreiras variam de acordo com o tipo de inovação, os atores do sistema de inovação envolvidos, o tipo de empresa, o setor econômico ao qual esta se insere, a localização da empresa e seu porte. Os dados da última Pintec revelam que, embora o número de empresas industriais respondentes tenha se reduzido comparativamente à edição anterior em $13 \%$ (i.e., de 118 mil a 103 mil), o número de firmas inovadoras que responderam sobre as percepçôes dos obstáculos reduziu-se em 16\% (gráfico A.1, no apêndice) e o das não inovadoras, em 18\% (gráfico A.2, no apêndice), o que indica, na média, menor percepção das empresas em relação aos obstáculos à inovação. Esse resultado pode decorrer, por um lado, da existência de programas e políticas públicas voltados ao fomento à inovação desenhados na última década do lado das empresas não inovadoras e, por outro, de um processo de aprendizado por parte das firmas inovadoras. 
A análise descritiva dos dados proposta neste artigo é a fase inicial de pesquisas que visam avançar o entendimento das relaçóes entre o tamanho das empresas e os obstáculos enfrentados em seus processos inovativos. Estudos futuros poderiam abranger o tipo de inovação, diferenças setoriais e o porte das empresas na percepção dos obstáculos à inovação (Zahler, Goya e Caamaño, 2018). Ademais, estudos utilizando os microdados da Pintec certamente permitirão avançar na compreensão entre obstáculos à inovação e o porte das empresas.

\section{REFERÊNCIAS}

ACEMOGLU, D.; ROBINSON, J. Why nations fail: the origins of powerprosperity and poverty. New York: Crown Books, 2012.

ARTHUR, W. B. The nature of technology: what it is and how it evolves. New York: Free Press, 2009.

AVELLAR, A. P. M.; BOTELHO, M. R. Políticas de apoio à inovação em pequenas empresas: evidências sobre a experiência brasileira recente. Economia e Sociedade, v. 24, n. 2, p. 379-417, 2015.

BASTOS, C.; REBOUÇAS, M.; BIVAR, W. A construção da Pesquisa Industrial de Inovação Tecnológica (Pintec). In: VIOTTI, E. B.; MACEDO, M. D. M. (Eds.). Indicadores de ciência, tecnologia e inovação no Brasil. Campinas: Editora da Unicamp, 2003.

BORRÁS, S.; EDQUIST, C. Education, training and skills in innovation policy. Science \& Public Policy, v. 42, n. 2, p. 215-227, 2015.

BOSWORTH, D. Barries to growth: the labour market. In: BARBER, J. et al. (Eds.). Barriers to growth in small firms. New York: Routledge, 1989.

BRASIL. Lei Complementar no ${ }^{123}$, de 14 de dezembro de 2006. Institui o Estatuto Nacional da Microempresa e da Empresa de Pequeno Porte. Diário Oficial, Brasília, 2006. Disponível em: <https://bit.ly/315GRtX>. Acesso em: 24 set. 2018.

CANAAN, R. G. Financiamento à inovaçáo em biotecnologia: uma avaliação da atuação da Finep no aporte de recursos não reembolsáveis. 2016. 104 f. Dissertação (Mestrado) - Universidade Federal de Minas Gerais, Belo Horizonte, 2016.

CANEPA, A.; STONEMAN, P. Financial constraints to innovation in the UK: evidence from CIS2 and CIS3. Oxford Economic Papers, v. 60, n. 4, p. 711730, 2008.

CANO, W. A desindustrialização no Brasil. Economia \& Sociedade, v. 21, número especial, p. 831-851, 2012. 
CARVALHO, L. R. A valsa brasileira. São Paulo: Todavia Livros, 2018.

CAVALCANTE, L. R.; DE NEGRI, F. A trajetória recente dos indicadores de inovaçáo no Brasil. Brasília: Ipea, 2011. (Texto para Discussão, n. 1659).

CHANDLER JUNIOR; A. D. Scale and scope: the dynamics of industrial capitalism. Cambridge: The Belknap Press of Harvard University Press, 1990. 760 p. COAD, A.; PELLEGRINO, G.; SAVONA, M. Barriers to innovation and firm productivity. Economics of Innovation and New Technology, v. 25, n. 3, p. 321-334, 2016.

CONNER, K. R.; PRAHALAD, C. K. A resource-based theory of the firm: knowledge versus opportunism. Organization Science, v. 7, n. 5, p. 477-501, 1996.

D'ESTE, P. et al. What hampers innovation? Revealed barriers versus deterring barriers. Research Policy, v. 41, n. 2, p. 482-488, Mar. 2012.

ETZKOWITZ, H.; LEYDESDORFF, L. The dynamics of innovation: from national systems and "mode 2" to a triple helix of university-industry-government relations. Research Policy, v. 29, n. 2, p. 109-123, Feb. 2000.

FIESP - FEDERAÇÃO DAS INDÚSTRIAS DO ESTADO DE SÃO PAULO. Obstáculos à inovaçáo. São Paulo: Decomtec/Fiesp, 2010.

FREEL, M. S. Barriers to product innovation in small manufacturing firms. International Small Business Journal, v. 18, n. 2, p. 60-80, 2000.

FURTADO, A.; QUEIROZ, S. A construção de indicadores de inovação. Revista Inovação Uniemp, n. 2, p. 26-28, 2005.

GALA, P.; RONCAGLIA, A. Brasil, uma economia que não aprende: novas perspectivas para entender o nosso fracasso. [s.l.]: [s.n.], 2020.

HADJIMANOLIS, A. The barriers approach to innovation. In: SHAVININA, L. V. (Ed.). The international handbook on innovation. Kidlington: Elsevier Science Ltd., 2003. p. 559-573.

HEWITT-DUNDAS, N. Resource and capability constraints to innovation in small and large plants. Small Business Economics, v. 26, p. 257-277, 2006.

IBGE - INSTITUTO BRASILEIRO DE GEOGRAFIA E ESTATÍSTICA. Demografia das empresas. Rio de Janeiro: IBGE, 2012. Disponível em: <https:// bit.ly/3o0ppZP>. Acesso em: 24 set. 2018.

Pesquisa de Inovação - Pintec, 2011. Rio de Janeiro: IBGE, 2013.

Disponível em: <https://bit.ly/2JdLSUi>. Acesso em: 24 set. 2018. 
Pesquisa de Inovaçáo - Pintec, 2014. Rio de Janeiro: IBGE, 2016. Disponível em: <https://is.gd/97UQ1A $>$.

KÜHL, M. R.; CUNHA, J. C. D. Obstacles to implementation of innovations in Brazil: how different companies perceive their importance. Brazilian Business Review, v. 10, n. 2, p. 1-24, 2013.

LUNDVALL, B.-Å. National systems of innovation: towards a theory of innovation and interactive learning. London: Pinter, 1992.

LUNDVALL, B.-Å.; JOHNSON, B. The learning economy. Journal of Industrial Studies, v. 1, n. 2, p. 23-42, 1994.

MAIA, M. D. M. A.; SILVA-FILHO, J. C. L. Obstáculos à inovação na indústria brasileira: uma análise setorial. Revista Tecnologia e Sociedade, v. 12, n. 26, p. 135-154, 2016.

MALERBA, F. Learning by firms and incremental technological change. The Economic Journal, v. 102, n. 413, p. 845-859, 1992.

MOHNEN, P.; ROSA, J. Les obstacles à l'innovation das les industries de services au Canada. Revue d'Analyse Économique, v. 77, n. 2, p. 231-254, 2001.

MOLINA-YCAZA, D.; SÁNCHEZ-RIOFRÍO, A. Obstáculos para la micro, pequeña y mediana empresa en América Latina. Pymes, Innovación y Desarrollo, v. 4, n. 2, p. 21-36, 2016.

MORCEIRO, P. C.; GUILHOTO, J. J. M. Adensamento produtivo e esgarçamento do tecido industrial brasileiro. Economia e Sociedade, 2020. No prelo.

NELSON, R. R. Why do firms differ and how does it matter. Strategic Management Journal, v. 12, special issue, p. 61-74, 1991.

NELSON, R. R.; WINTER, S. Uma teoria evolucionária da mudança econômica. 1. ed. Campinas: Editora da Unicamp, 2005. 632 p.

OLIVEIRA, C. E. D. Problemas e obstáculos para a realização de inovações em empresas brasileiras. Revista Brasileira de Gestáo e Inovação, v. 3, n. 1, p. 93 $112,2015$.

OLIVEIRA, V. P. Relacionamentos cooperativos entre pequenas e médias empresas brasileiras e universidades e institutos públicos de pesquisa: uma investigação sobre os fatores direcionadores (drivers) da interação e dos tipos de relacionamento. 2019. Tese (Doutorado) - Instituto de Economia, Universidade Estadual de Campinas, Campinas, 2019. 
OLIVEIRA, V. P.; BERTONI, R. B. Problemas e obstáculos à inovação em pequenas e médias empresas no Brasil: uma discussão a partir da Pesquisa de Inovação (Pintec). Revista Pymes, Innovación y Desarrollo, v. 2, n. 3, p. 4-29, 2014.

PELLEGRINO, G.; SAVONA, M. Is money all? Financing versus knowledge and demand constraints to innovation. Maastricht: Unu-Merit, 2013. (Working Paper Series, n. 2013-029).

PENROSE, E. A teoria do crescimento da firma. Campinas: Editora da Unicamp, 2006. 398 p.

RAPINI, M. S. Padráo de financiamento aos investimentos em inovaçáo no Brasil. Belo Horizonte: Cedeplar/UFMG, 2013. (Texto para Discussão, n. 497). RAPINI, M. S.; CHIARINI, T.; BITTENCOURT, P. F. Obstacles to innovation in Brazil: the lack of qualified individuals to implement innovation and establish university-firm interactions. Industry and Higher Education, v. 31, n. 3, p. 168-183, 2017.

REBOUÇAS, M. Pintec: pequenas empresas mostram melhor desempenho. Entrevistadores: Simone Pallone e Wanda Jorge. Inovaçáo Uniemp, Campinas, v. 1, n. 3, p. 6-9, 2005.

REIS, E. A.; REIS, I. A. Análise descritiva de dados. Belo Horizonte: Departamento de Estatística da UFMG, 2002. (Relatório Técnico). Disponível em: $<$ https://bit.ly/2J2Y4aM>. Acesso em: 17 jan. 2019.

ROTHWELL, R. Small firms, innovation and industrial change. Small Business Economics, v. 1, n. 1, p. 51-64, 1989.

SCHUMPETER, J. A. Capitalism, socialism and democracy. 3nd ed. New York: Harper Perennial Modern Thought, 2008. 431 p.

SEBRAE - SERVIÇO BRASILEIRO DE APOIO ÀS MICRO E PEQUENAS EMPRESAS. Anuário do Trabalho na Micro e Pequena Empresa. Brasília: Dieese, 2013. Disponível em: <https://bit.ly/2HDUaUP>. Acesso em: 24 set. 2018.

SILVA, D. R. M.; FURTADO, A. T. Modelos teóricos e interesses de mensuração no surgimento da pesquisa e inovação brasileira (Pintec). Revista Brasileira de Inovaçáo, v. 16, n. 1, p. 97-128, 2017.

SILVA-FILHO, J. C. L.; BRAGA, C. S. C.; REBOUÇAS, S. M. D. P. Percepção de obstáculos à inovação na indústria brasileira de transformação International Journal of Innovation, v. 5, n. 1, p. 114-131, 2017.

SILVA, L. A.; RAPINI, M. S.; SCHULTZ, S. Instrumentos financeiros de apoio à inovação: como é a participação das empresas mineiras. In: SEMINÁRIO SO- 
BRE A ECONOMIA MINEIRA, 2010, Diamantina, Minas Gerais. Anais... Diamantina: Cedeplar, 2010.

TANG, H.-K.; YEO, K.-T. Innovation under constraints: the case of Singapore. In: SHAVININA, L. V. (Ed.). The International Handbook on Innovation. Kidlington: Elsevier Science Ltd., 2003. p. 873-881.

ZAHLER, A.; GOYA, D.; CAAMAÑO, M. The role of obstacles to innovation on innovative activity: an empirical analysis. In: LALICS CONFERENCE, 2018. Ciudad de Mexico, Mexico. Anais... Ciudad de Mexico: Globelics, 2018. ZEVALLOS, E. Micro, pequeñas y medianas empresas en América Latina. Revista de la Cepal, n. 79, p. 53-70, 2003. 


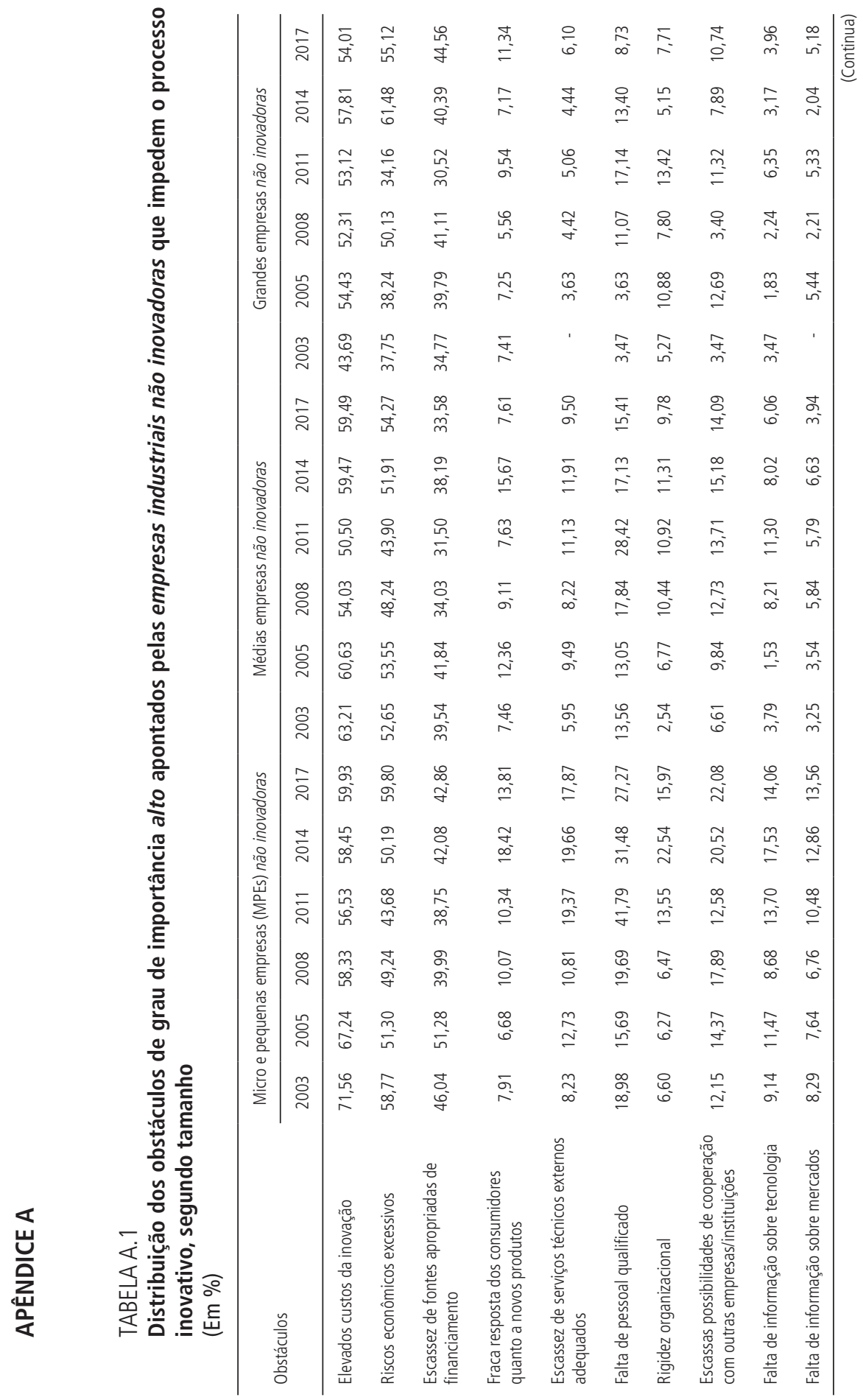


Obstáculos à Inovação e Porte das Empresas Industriais no Brasil: rumo a políticas públicas

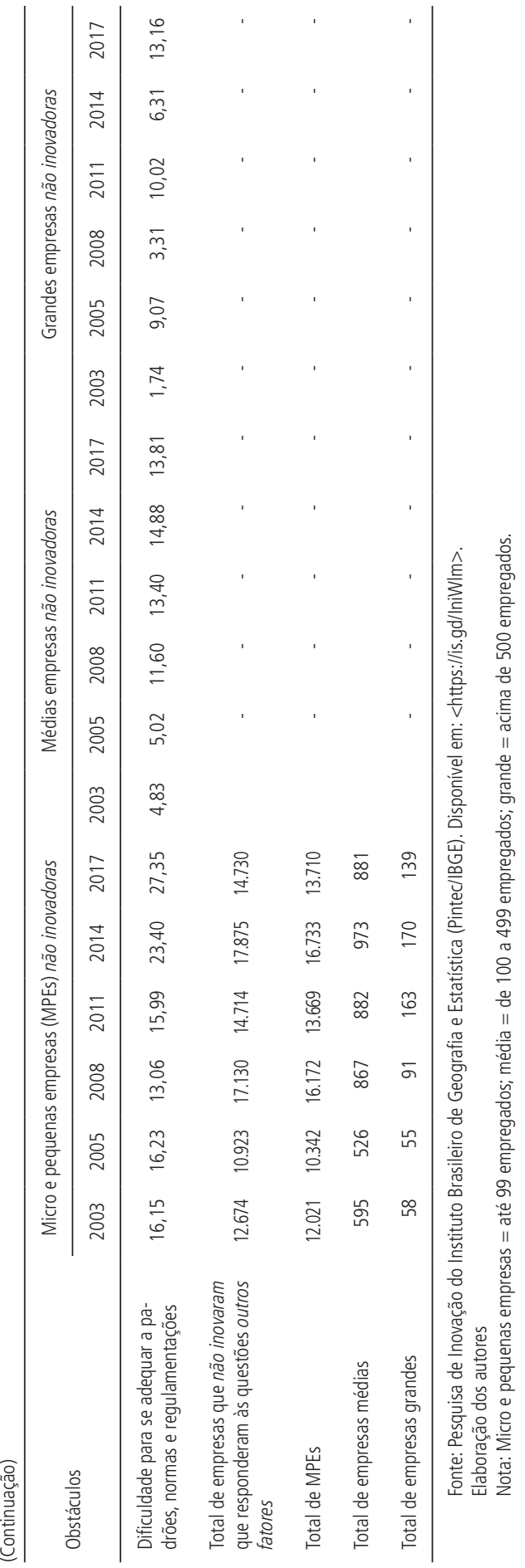




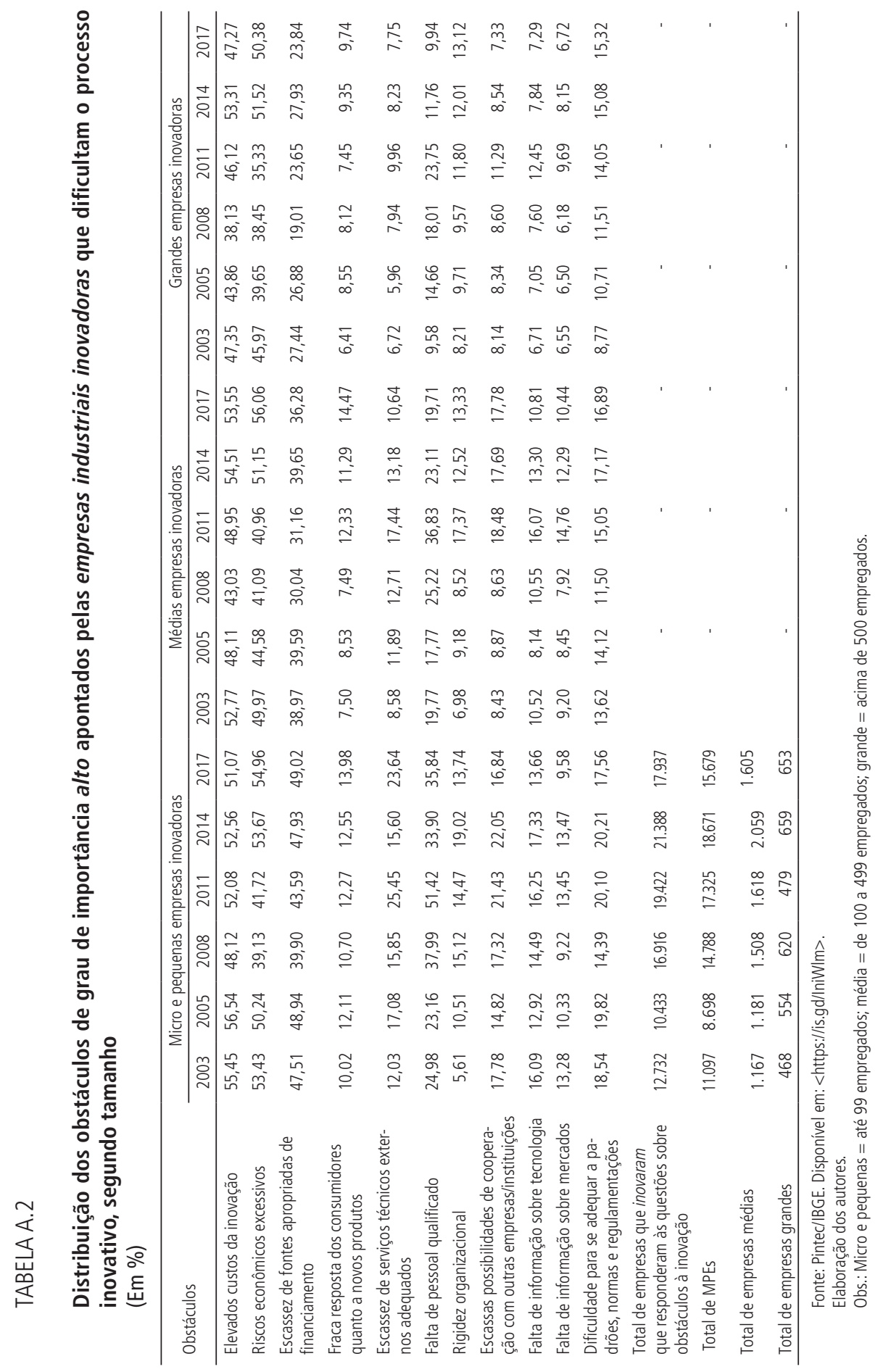


GRÁFICO A.1

Evolução do total de empresas industriais que responderam à Pintec, total das inovadoras que responderam às questões concernentes aos obstáculos à inovação e percentual, por porte

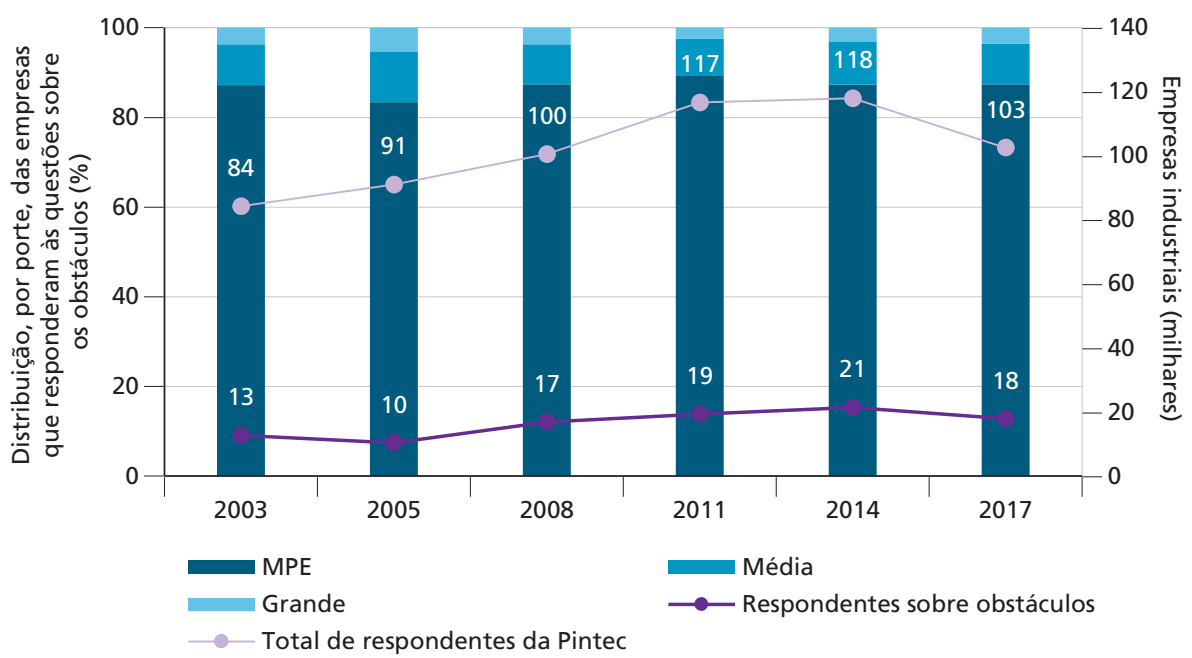

Fonte: Pintec/IBGE. Disponível em: <https://is.gd/lniWIm>.

Elaboração dos autores.

\section{GRÁFICO A.2}

Evolução do total de empresas industriais que responderam à Pintec, total das não inovadoras que responderam às questões concernentes aos obstáculos à inovação e percentual, por porte

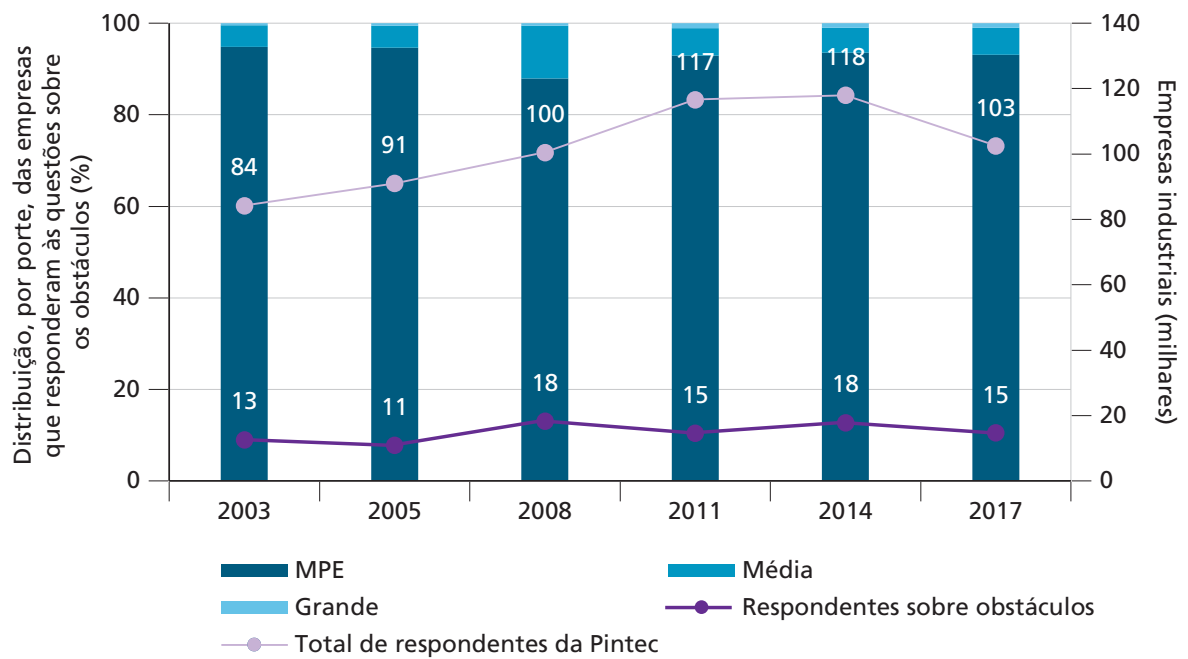


Data da submissão: 18/5/2018

Primeira decisão editorial em: 25/10/2018

Última versão recebida em: 4/2/2019

Aprovação final em: 18/2/2019 